Check for updates

Cite this: J. Mater. Chem. A, 2017, 5 , 21542

Received 8th August 2017

Accepted 20th September 2017

DOI: $10.1039 / c 7 t a 06969 c$

rsc.li/materials-a

\section{Metal organic framework derived mesoporous carbon nitrides with a high specific surface area and chromium oxide nanoparticles for $\mathrm{CO}_{2}$ and hydrogen adsorption $\uparrow$}

\begin{abstract}
Stalin Joseph, (DD a Devaraju M. Kempaiah, ${ }^{\text {*a }}$ Mercy Benzigar, ${ }^{a}$ Arun V. Baskar, ${ }^{a}$ Siddulu N. Talapaneni, ${ }^{\text {*a }}$ Sung Hwa Jhung, ${ }^{\text {b Dae-Hwan Park }}{ }^{\mathrm{a}}$ and Ajayan Vinu (D) *a

In this work, we report a simple and versatile method for the preparation of mesoporous carbon nitrides (MCNs) functionalized with highly dispersed chromium oxide nanoparticles by using a metal organic framework, MIL-100(Cr), as a template and aminoguanidine hydrochloride (AG) as a high nitrogen content single molecular precursor. We are able to synthesise these metal oxide functionalized MCN materials with single step carbonization but without using any toxic template removal process using $\mathrm{HF}$ or $\mathrm{NaOH}$. The absence of a washing procedure with toxic acid also allows the incorporation of a large amount of metal oxide particles inside the porous channels of MCNs. The obtained MCN materials exhibit a high specific surface area and a large pore volume. The AG to template ratios are varied to control the amine functional groups and the textural parameters including the specific surface area and pore volume. It is found that the AG to template ratio of 1.5 is the best condition to obtain MCNs with a specific surface area of $1294 \mathrm{~m}^{2} \mathrm{~g}^{-1}$, which is the highest value reported so far for MCN-based materials. FT-IR and XPS results reveal that the prepared materials contain free $\mathrm{NH}_{2}$ groups within the $\mathrm{CN}$ network which help to anchor metal oxide nanoparticles and provide highly dispersed basic sites. These functionalized MCN materials are also used as adsorbents for $\mathrm{CO}_{2}$ capture. Among the materials studied, the MCN with the highest specific surface area shows the largest $\mathrm{CO}_{2}$ adsorption capacity (16.8 $\mathrm{mmol} \mathrm{g}^{-1}$ ) which is much higher than those of MCN materials prepared from SBA-15 and KIT-6, activated carbon, MIL-100(Cr), SBA-15, and multiwalled carbon nanotubes. This high adsorption capacity is mainly due to the strong synergistic effect between the MCN with high specific surface area and highly dispersed metal oxide nanoparticles.
\end{abstract}

\section{Introduction}

The rapid growth of energy consumption in the form of fossil fuels creates a lot of problems for the atmosphere due to the enormous $\mathrm{CO}_{2}$ emission. ${ }^{1-5}$ The as-emitted $\mathrm{CO}_{2}$ can be captured and utilized for several applications such as energy storage, production of chemicals, synthesis of polycarbonate plastics, biological conversion, mineralization and fuel recovery, etc. ${ }^{1}$ Porous adsorbents such as mesoporous silica, micro and mesoporous carbons and porous carbon nitrides have been widely used as adsorbents for the capture of $\mathrm{CO}_{2}$ owing to their well-

${ }^{a}$ Future Industries Institute (FII), University of South Australia (UniSA), Mawson Lakes Campus, Mawson Lakes, SA 5095, Australia. E-mail: Devaraju. MurukanahallyKempaiah@unisa.edu.au; siddulunaidu@gmail.com; Ajayan.Vinu@ newcastle.edu.au

${ }^{b}$ Department of Chemistry, Green-Nano Materials Research Center, Kyungpook National University, Daegu 41566, Republic of Korea

$\dagger$ Electronic supplementary information (ESI) available. See DOI: 10.1039/c7ta06969c ordered porous structures, high specific surface areas and large pore volumes. ${ }^{6-9}$ Among these adsorbents, mesoporous carbon nitrides (MCNs) are quite unique as they can not only offer well-ordered porous structures and semiconducting properties but also provide basic adsorption sites that are in the form of $\mathrm{NH}$ or $\mathrm{NH}_{2}$ groups. ${ }^{\mathbf{1 0 - 1 2}}$ These basic sites help to enhance the adsorption of $\mathrm{CO}_{2}$ molecules which are slightly acidic in nature through a simple acid-base interaction. ${ }^{\mathbf{1 0 , 1 1}}$

MCNs are generally synthesized by the nanohard templating approach using mesoporous silicas as templates. ${ }^{12}$ The properties of the MCN materials can be controlled with a simple adjustment of the structure and pore diameter of the templates and the nature of the nitrogen precursors. With this approach, several MCNs with a large surface area, tuneable pore diameters, and different nitrogen contents have been prepared and used for various other applications including catalysis, sensing, and energy storage and conversion. ${ }^{13-17}$ For example, since the first report of MCNs by Vinu et al. in $2005,{ }^{18}$ various templating approaches such as hard nanocasting and soft self-assembly have 
been employed for the synthesis of different MCN materials. ${ }^{\mathbf{1 8 - 2 2}}$ Among them, the nanocasting method was found to be an effective way to prepare highly ordered MCN materials and various porous silicas with different structures such as SBA-15, SBA-16, ${ }^{23}$ KIT-6, and IBN-4 have been widely used as templates. ${ }^{19-21,24-26}$ This silica templating process generally includes three main steps: (i) infiltration of precursors into the silica template; (ii) polymerization and cross-linking of the carbon and nitrogen precursors into the MCN material at high temperature; and (iii) removal of the silica template with a toxic washing procedure using HF. However, these traditional porous silica templates are expensive and complicated as they involve highly toxic substances such as HF to remove the silica, which limits their use in multifunctional applications with large scale production. By replacing the inorganic templates with organic templates, various steps including the toxic HF treatment, washing with expensive solvents such as ethanol and long synthesis time could be avoided. This simple and single step approach could remove the hurdle in the path of the commercialization of MCNs and help to produce MCN materials in a safe and cost effective way.

Metal-organic frameworks (MOFs) have been considered as a new kind of porous material and also attracted much attention owing to their high adsorption capacities and tuneable pore diameters which make them suitable for various potential applications such as gas separation, storage, catalysis and drug delivery. ${ }^{27-31}$ The unlimited combinations of organic and inorganic building blocks have offered enormous flexibility to MOFs with high chemical and thermal stability. Among these MOFs, MIL-100(Cr $)^{32}$ with a chemical composition of $\mathrm{Cr}_{3} \mathrm{O}(\mathrm{F} / \mathrm{OH})\left(\mathrm{H}_{2}-\right.$ $\mathrm{O})_{2}\left[\mathrm{C}_{6} \mathrm{H}_{3}\left(\mathrm{CO}_{2}\right)_{3}\right]_{2} \cdot n \mathrm{H}_{2} \mathrm{O}$ has great potential due to its large surface area up to $3340 \mathrm{~m}^{2} \mathrm{~g}^{-1}$, high pore volume $\left(1.16 \mathrm{~cm}^{3} \mathrm{~g}^{-1}\right)$, accessible microporous windows of $c a$. 0.5 and $0.9 \mathrm{~nm}$, unsaturated chromium sites, unexpectedly high thermal stability (above $300{ }^{\circ} \mathrm{C}$ ), and rigid structural integrity even after prolonged immersion in water. ${ }^{33}$ These exciting properties make it an excellent organic templating agent for the fabrication of mesoporous materials including MCNs. However, most of the research on MIL-100(Cr) focused mainly on the structural functionalization and applications in selective adsorption, separation, storage, and catalysis. ${ }^{34,35}$ By utilising this unique material as a template, not only mesoporous materials could be generated but also with ultra-fine and highly dispersed metal oxide nanoparticles in the pore channels of the mesoporous materials. However, so far, no research has been conducted on using this material as a template for the preparation of MCNs.

Here we describe a silica free, simple and direct synthesis of MCN materials functionalized with chromium oxide nanoparticles and with a large surface area using MIL-100(Cr) as a hard template via a simple thermo-polymerisation of aminoguanidine as a single molecular $\mathrm{C}$ and $\mathrm{N}$ precursor. To the best of our knowledge, this is the first report on the preparation of MCN materials using a microporous MOF as a sacrificial template along with the incorporation of chromium oxide onto the surface of the MCN materials. The advantages of using porous MIL-100(Cr) as a template are the presence of nanoscale cavities and an open channel structure which could be beneficial in infiltrating the small $\mathrm{CN}$ precursor molecules into its open channels to obtain MCN with a high surface area and large pore volume. The prepared MCN exhibits much higher $\mathrm{CO}_{2}$ adsorption capacity than activated carbon, MWCNTs, mesoporous silica, the parent template MIL-100(Cr) and MCN prepared from the SBA-15 template. This simple but effective method can be utilized for the preparation of various MCN nanostructures from different MOFs.

\section{Experimental}

\subsection{Synthesis of MIL-100(Cr)}

For the preparation of MIL-100(Cr), a reflux process was carried out using trimesic acid, metallic chromium, $\mathrm{HF}, \mathrm{HNO}_{3}$ and $\mathrm{H}_{2} \mathrm{O}$ as starting materials. The definite amounts of these precursors (trimesic : $\mathrm{Cr}: \mathrm{HF}: \mathrm{HNO}_{3}: \mathrm{H}_{2} \mathrm{O}$ in a $1: 1: 0.2: 0.5: 100$ weight ratio) were refluxed at $95{ }^{\circ} \mathrm{C}$ for $12 \mathrm{~h}$ under atmospheric pressure. After the refluxing duration, materials were recovered through purification by washing with hot distilled water and then dried under vacuum..$^{36-38}$ The final material was used as the template for the preparation of functionalized MCN.

\subsection{Synthesis of chromium oxide functionalized MCN materials}

Chromium oxide functionalized MCN materials were prepared through a hard-templating approach using the MIL-100(Cr) as a template (Scheme 1). In a typical synthesis, $1.5 \mathrm{~g}$ of aminoguanidine hydrochloride (AG) dissolved in $1.5 \mathrm{~g}$ of water was mixed with $1 \mathrm{~g}$ of MIL-100(Cr). The resultant MCN-MIL composite was heated at $100{ }^{\circ} \mathrm{C}$ for $6 \mathrm{~h}$ and further heated at $160{ }^{\circ} \mathrm{C}$ for another $6 \mathrm{~h}$ in a programmed oven. Subsequently, the composite was heated at $400{ }^{\circ} \mathrm{C}$ in a tubular furnace by flowing nitrogen (100 ml per minute) with a heating rate of $3{ }^{\circ} \mathrm{C} \mathrm{min}{ }^{-1}$ for about $5 \mathrm{~h}$ to achieve the polymerization and subsequent carbonization. A set of samples were prepared with different amounts of AG using the above procedure. The samples are denoted as Cr-MCN-10- $X$ where $X$ denotes the amount of AG in gram added to the synthesis mixture $(1.5,2.0$ and 2.5$) .{ }^{24,39}$

\section{$2.3 \quad \mathrm{CO}_{2}$ and $\mathrm{H}_{2}$ adsorption}

High pressure $\mathrm{CO}_{2}$ and $\mathrm{H}_{2}$ adsorption measurements were carried out on a Quantachrome Isorb HP1 equipped with a temperature controlled circulator. The $\mathrm{CO}_{2}$ adsorption test was carried out in the pressure range of 0 to 30 bar at 0 to $25^{\circ} \mathrm{C}$ after the samples were degassed for $8 \mathrm{~h}$ at $200{ }^{\circ} \mathrm{C}$. The $\mathrm{H}_{2}$ adsorption test was carried out at 0 to 50 bar at $50{ }^{\circ} \mathrm{C}$.

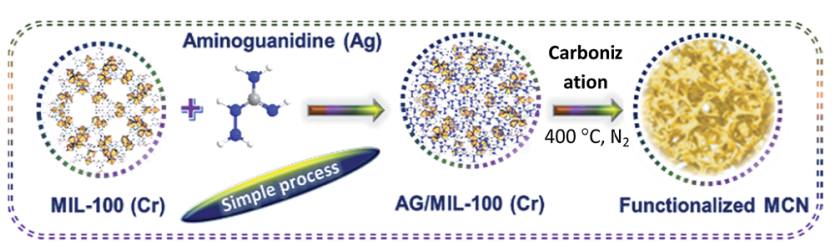

Scheme 1 Schematic diagram showing the formation of metal functionalized mesoporous carbon nitride. 


\section{Results and discussion}

\subsection{Structural analysis of $\mathrm{Cr}-\mathrm{MCN}-10$}

The structure of the Cr-MCN-10 was analysed by powder X-ray diffraction analysis. Fig. 1A shows the XRD patterns of both the template and Cr-MCN-10- $X$ samples. MIL-100(Cr) shows several peaks at higher angles associated with the cubic crystal system which are in agreement with the previous reports. ${ }^{32}$ Although the characteristic peaks of the template are clearly visible for MIL-100(Cr), MCN samples prepared with different amounts of AG using MIL-100(Cr) as a template exhibit no peaks in the higher angle associated with the MIL-100(Cr), indicating that the template was completely removed after the carbonization at a high temperature. It is noted that the less intense peaks of the graphitic carbon nitride are observed around $(2 \theta) 25.6^{\circ}$ and $\mathrm{ca}$. $44^{\circ}$, which can be attributed to the turbostratic ordering of $\mathrm{C}$ and $\mathrm{N}$ in the wall structure of the $\mathrm{CN}$ framework. ${ }^{12-23}$ The absence of high intensity peaks at higher angles related to $\mathrm{Cr}$ or chromium oxides also confirms that the Cr-based particles are finely dispersed on the pore walls of the Cr-MCN-10 samples and may be amorphous in nature.

The HRSEM images of the Cr-MCN-10-1.5 are shown in Fig. 1B and D. The Cr-MCN-10-1.5 possesses highly uniform spherical shaped particles that are highly interconnected and similar to those of the template. The size of the particles is in the range of 100 to $200 \mathrm{~nm}$. It is interesting to note that the macropores are formed between the particles whose sizes are in the range of a few to tens of micrometers. This may be due to the decomposition of the loosely held $\mathrm{CN}$ polymers that are decomposed at a high temperature, leaving large mesopores. The energy dispersive X-ray spectroscopy (EDS) pattern of the Cr-MCN-10-1.5 exhibits four sharp peaks which correspond to $\mathrm{C}, \mathrm{N}, \mathrm{O}$ and $\mathrm{Cr}$, revealing that the product is composed of carbon nitride and chromium oxide nanoparticles (Fig. 1C).
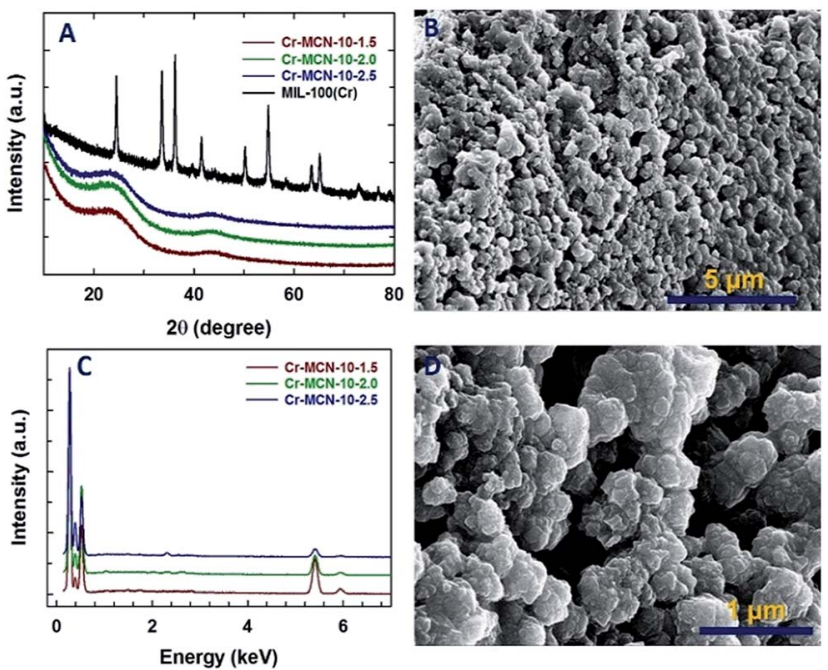

Fig. 1 (A) Wide angle XRD patterns of $\mathrm{Cr}-\mathrm{MCN}-10-X$ and the template MIL-100(Cr), (B) and (D) HRSEM images of $\mathrm{Cr}-\mathrm{MCN}-10-1.5$ and (C) energy dispersive $\mathrm{X}$-ray spectroscopy (EDS) patterns of $\mathrm{Cr}-\mathrm{MCN}-10-\mathrm{X}$.
From the intensity of the Cr peaks, it can be concluded that most of the Cr from the template is transferred to the final CrMCN-10 samples as chromium oxide nanoparticles. It is assumed that the $\mathrm{Cr}$ atoms reacted with the oxygen of the carboxyl groups in the templates to form the chromium oxide particles. The absence of the chlorine peak in the EDS pattern confirms that the precursor has completely undergone polymerization to form $\mathrm{CN}$ polymers and the hydrogen chloride from the precursor is completely removed during the high temperature carbonization process.

It is interesting to note that the intensity of the $\mathrm{N}$ peak in the EDS pattern increases concomitantly with the decrease in the intensity of the $\mathrm{Cr}$ peak as the amount of AG in the synthesis mixture is increased. This reveals that the content of chromium in the samples prepared with a high amount of AG is lower as compared to that of $\mathrm{Cr}-\mathrm{MCN}-10-1.5$. The N/C ratio calculated from the EDS is $0.95-0.46$ which is lower than that obtained from the mesoporous silica-based templating procedure (1.33 to 1.9), suggesting that carbon from the template takes part in the reaction. ${ }^{39}$ This is again confirmed by the fact that the N/C ratio increases with increasing the amount of the precursor in the synthesis mixture. It should also be noted that the particles are agglomerated when the loading of AG is increased in the synthesis mixture (Fig. 1S $\dagger$ ). This might be attributed to the formation of $\mathrm{CN}$ polymers around the template particles which tend to interact with the neighbouring particles during the polymerization process.

The porosity of the Cr-MCN-10-1.5 is further investigated by high resolution transmission electron microscopy (HRTEM). The HRTEM images reveal that the material is mainly composed of small and slightly disordered mesopores that are quite interconnected and in the size range of 2 to $3 \mathrm{~nm}$ (Fig. 2A and $\mathrm{B}$ ). The elemental mapping of $\mathrm{Cr}-\mathrm{MCN}-10-1.5$ further confirms the presence of $\mathrm{C}, \mathrm{N}, \mathrm{O}$ and $\mathrm{Cr}$ in the sample. A homogenous distribution of these elements throughout the sample further reveals that the sample is highly uniform and chromium oxide nanoparticles are evenly distributed in the porous channels of the MCN matrix. A similar mesostructure and homogeneous distribution of elements are also observed for other Cr-MCN-10 samples (Fig. 2S to $6 \mathrm{~S} \dagger$ ).
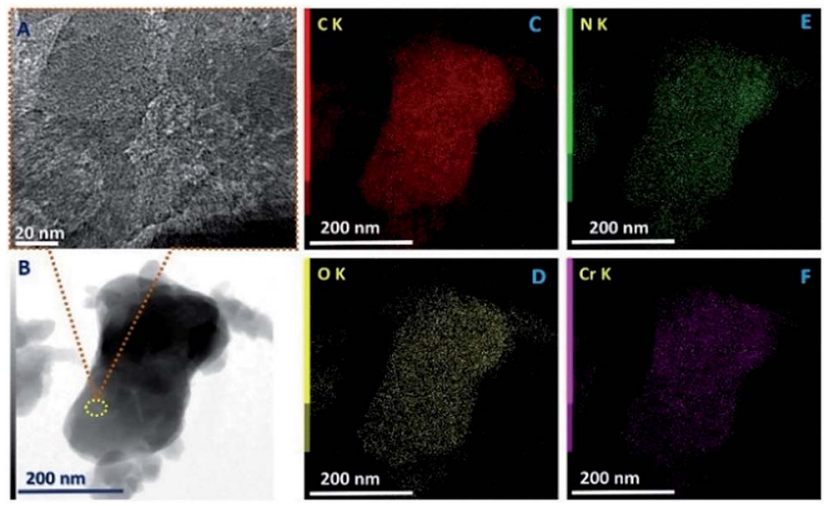

Fig. 2 (A) HRTEM image, (B) bright field scanning TEM image, and (CF) elemental mapping of $\mathrm{Cr}-\mathrm{MCN}-10-1.5$, showing the distribution of carbon, nitrogen chromium and oxygen, respectively. 
3.2 Surface area and pore size analysis by nitrogen adsorption

The nitrogen adsorption-desorption isotherms of Cr-MCN-10 materials are shown in Fig. 3A, and the corresponding textural parameters are summarised in Table 1. All the samples show a type IV adsorption isotherm, which is characteristic of porous materials with a mesopore size distribution. The isotherms also show a broad condensation step at lower relative pressure, indicating a small mesopore size. This kind of broad condensation step is a rather peculiar characteristic of materials with bimodal pores or cage like pore systems. These results reveal that the prepared materials have mesopores that indeed originate from the MIL-100(Cr) template due to the decomposition of organic moieties or the displacement of the metal species. There is also a broad hysteresis loop in all of the samples in a higher relative pressure region which is attributed to the large mesopores that originate from the interparticles. It is interesting to note that the amount of nitrogen adsorbed in the monolayer region of the isotherm for $\mathrm{Cr}-\mathrm{MCN}-10$ which is used for the calculation of the specific surface area is much higher than those of other MCN samples discovered so far. ${ }^{18,21,23,24,35,39-44}$ Interestingly, the sample prepared with a low
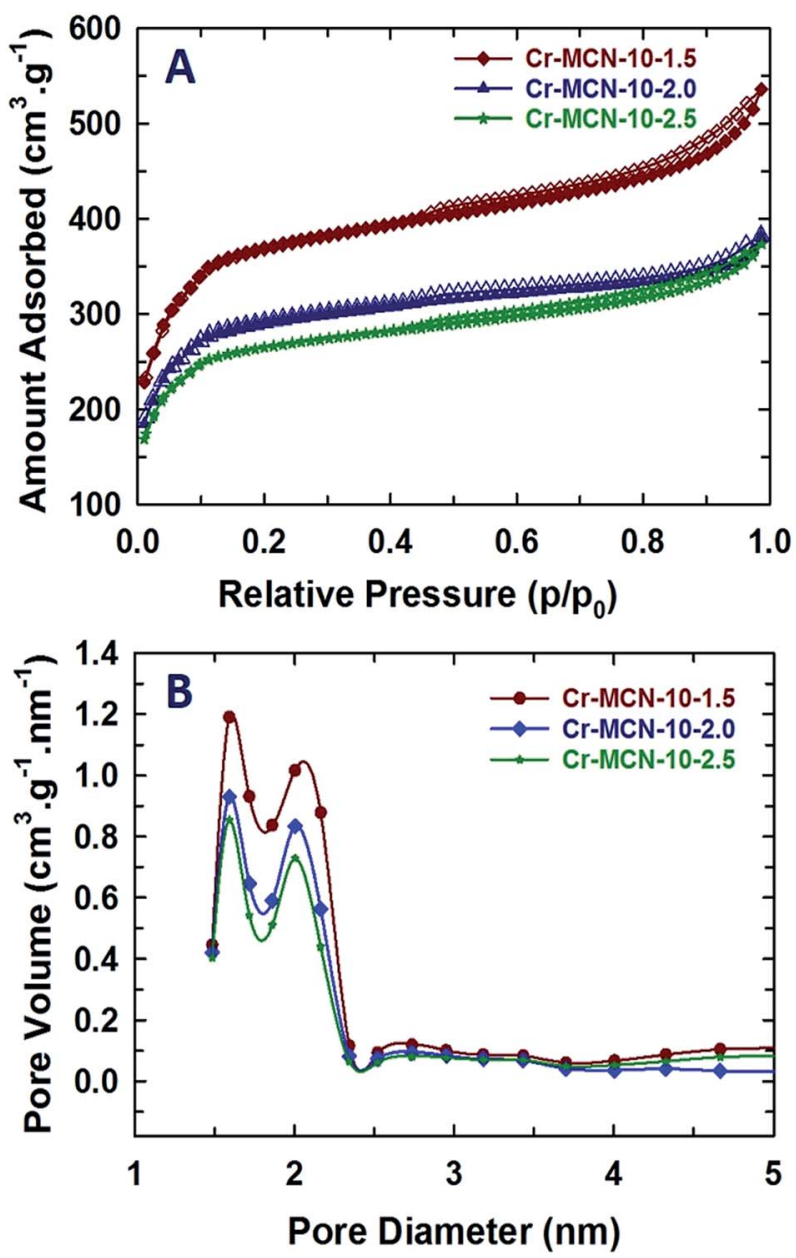

Fig. 3 (A) Nitrogen adsorption-desorption isotherms and (B) NLDFTpore size distributions of $\mathrm{Cr}-\mathrm{MCN}-10-X$ samples. amount of AG registered the highest amount of nitrogen adsorption in the monolayer region than other samples prepared in this study. This indicates that the specific surface area of the samples can be controlled by varying the amount of AG precursor. The textural information of all the samples including the specific surface area, micropore surface area, specific pore volume and pore diameters is shown in Table 1. The specific surface area and the specific pore volume of $\mathrm{Cr}$ MCN-10-1.5 are $1294 \mathrm{~m}^{2} \mathrm{~g}^{-1}$ and $0.42 \mathrm{~cm}^{3} \mathrm{~g}^{-1}$, respectively. It has been noted that the specific surface area, pore volume and pore diameter of the samples decrease from 1294 to $921 \mathrm{~m}^{2} \mathrm{~g}^{-1}$, 0.42 to $0.0 .27 \mathrm{~cm}^{3} \mathrm{~g}^{-1}$, and 2.10 to $2.0 \mathrm{~nm}$, respectively, as the amount of AG is increased (Table 1). The highest specific surface area of Cr-MCN-10-1.5 mainly originates from the micropores in the sample. This is clearly confirmed by the fact that the micropore area of this sample $\left(771 \mathrm{~m}^{2} \mathrm{~g}^{-1}\right)$ is much higher than those of other samples used in this study. However, the specific surface area of the non-porous carbon nitride prepared without the MIL-100(Cr) template is less than $25 \mathrm{~m}^{2} \mathrm{~g}^{-1}$. It is interesting to note that all the samples possess bi-modal pores with both micro and mesopores. These pores are formed due to the decomposition of MIL-100(Cr) frameworks during the carbonisation process, in which MIL-100(Cr) behaved as a selfsacrificial template as well as a Cr source for the in situ incorporation of chromium oxides onto the porous surface of Cr-MCN-10. It should be noted that when the amount of AG of $1.0 \mathrm{~g}$ was used, the yield of the sample was too low and not enough for the characterization.

\subsection{Chemical structure analysis of $\mathrm{Cr}-\mathrm{MCN}-10$}

Fig. 4A shows the representative electron energy loss spectrum of Cr-MCN-10-1.5. It can be clearly seen that the sample displays sharp $\mathrm{C}-\mathrm{K}, \mathrm{N}-\mathrm{K}$ and $\mathrm{Cr}-\mathrm{L}$ ionization edges that are located at $290.9,404.2$, and $579.4 \mathrm{eV}$, respectively. The peak at $290.9 \mathrm{eV}$ is attributed to the $1 \mathrm{~s}-\pi^{*}$ transition which is caused by the difference in the electron density of $\mathrm{C}$ and $\mathrm{N}$ due to their different electronegativities. This feature is usually seen for $\mathrm{sp}^{2}$ hybridized carbon in graphite or graphene-based samples and further confirms a strong bonding between the $\mathrm{C}$ and $\mathrm{N}$ atoms and the $\mathrm{C}$ atoms are $\mathrm{sp}^{2}$ hybridised with nitrogen. The peak at $404.2 \mathrm{eV}$ also confirms that the nitrogen atoms are $\mathrm{sp}^{2}$ hybridised with carbon. The sample also shows a higher energy loss which corresponds to the $1 \mathrm{~s}-\sigma^{*}$ transition in both $\mathrm{C}-\mathrm{K}$ and $\mathrm{N}-\mathrm{K}$ ionization edges, revealing a perfect $\mathrm{sp}^{2}$ hybridization between the $\mathrm{C}$ and $\mathrm{N}$ atoms. A similar feature was also observed for previously reported $\mathrm{MCN}$-based samples ${ }^{23}$ but in this case the energy loss for the $\mathrm{N}-\mathrm{K}$ ionization edges is slightly higher. This might be attributed to the presence of the tetrazine structure in the CN walls of MCN. The Cr-L3 peak appears at $581.1 \mathrm{eV}$ whereas the Cr-L2 split peak is seen at $589.8 \mathrm{eV}$. These peaks are similar to those observed for chromium oxide nanoparticles and the peak positions are also identical to those observed by Daulton et al. ${ }^{45}$ A minor and broad peak that is related to oxygen is seen at higher energy which also confirms the presence of chromium oxide nanoparticles in the sample. As previously mentioned, the chromium oxide nanoparticles are formed by 
Table 1 Textural parameters and EDS analysis of $\mathrm{Cr}-\mathrm{MCN}-10-\mathrm{X}$ samples

\begin{tabular}{|c|c|c|c|c|c|c|c|c|c|}
\hline & & & $\begin{array}{l}\text { Micropore area } \\
\left(\mathrm{m}^{2} \mathrm{~g}^{-1}\right)\end{array}$ & Pore diameter (nm) & \multicolumn{5}{|c|}{ EDS analysis (wt\%) } \\
\hline Cr-MCN-10-2.0 & 1013 & 0.29 & 641 & $1.57,2.03$ & 53.8 & 25.8 & 3.1 & 17.3 & 0.48 \\
\hline Cr-MCN-10-2.5 & 921 & 0.27 & 583 & $1.57,2.00$ & 42.4 & 40.7 & 0.8 & 16.1 & 0.95 \\
\hline
\end{tabular}
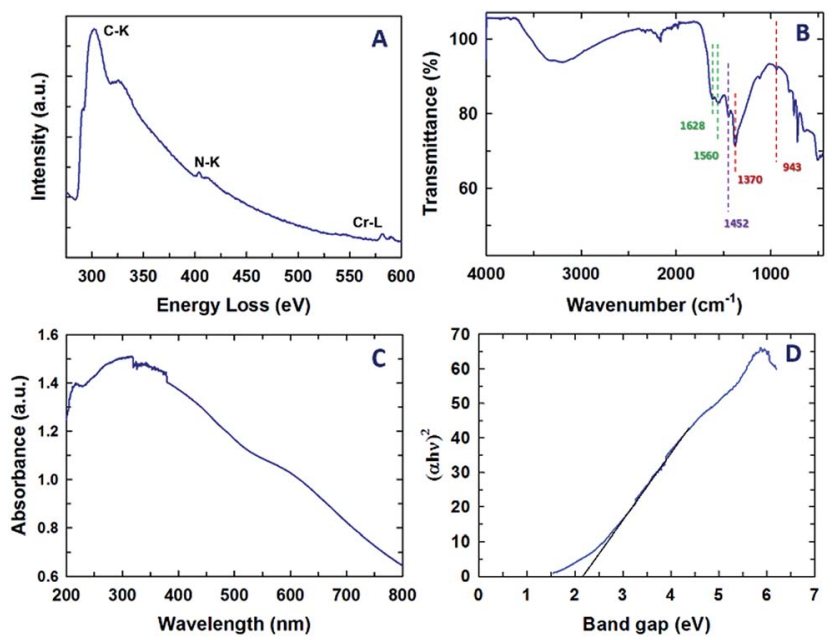

Fig. 4 (A) Electron energy loss spectrum, (B) FT-IR spectrum, (C) UV$V$ is spectrum and (D) bandgap data of the $\mathrm{Cr}-\mathrm{MCN}-10-1.5$ sample.

the reaction between the chromium atoms and the carboxyl functional groups present in the template.

Information on the chemical bonding between the carbon and nitrogen atoms in the $\mathrm{Cr}-\mathrm{MCN}-10$ material was also obtained from FT-IR. The FT-IR spectrum of Cr-MCN-10-1.5 is shown in Fig. 4B. The stretching mode observed in the region 1628 and $1560 \mathrm{~cm}^{-1}$ is assigned to the characteristic vibrations of aromatic $\mathrm{C}=\mathrm{N}$, which is also observed for non-porous $\mathrm{CN}$ prepared from AG precursors. The peaks at 943 and $1370 \mathrm{~cm}^{-1}$ also represent the typical tetrazine rings. ${ }^{46}$ Another band at $1450 \mathrm{~cm}^{-1}$ is assigned to the graphitic $\mathrm{C}-\mathrm{N}$ band owing to the aromatic ring in the structure. ${ }^{47}$ The stretching mode between 3150 and $3350 \mathrm{~cm}^{-1}$ is attributed to the $\mathrm{N}-\mathrm{H}$ stretching of $\mathrm{NH}_{2}$ groups attached to the $\mathrm{sp}^{2}$ hybridized carbon framework, which coincides with the previous reports. ${ }^{12,25}$ These results obviously support the presence of a $\mathrm{CN}$ polymeric network of the carbon nitride structure.

The UV-visible diffuse reflectance spectrum of Cr-MCN-101.5 and its corresponding bandgap data are shown in Fig. 4C and D, respectively. Two broad peaks are observed at 250 and $320 \mathrm{~nm}$ and a large broad peak in the visible region (400 to $600 \mathrm{~nm}$ ) was also observed. The peaks at lower wavelengths are attributed to the $\pi-\pi^{*}$ or $\mathrm{n}-\pi^{*}$ transitions in the aromatic $\mathrm{CN}$ framework. It is interesting to note that the bandgap of $\mathrm{Cr}$ MCN-10-1.5 is determined to be $2.2 \mathrm{eV}$ from the ultravioletdifferential reflectance spectrum as shown in Fig. 3D. The pure MCN materials have the energy bandgap of $2.7 \mathrm{eV}$ whereas the MCN prepared from AG using mesoporous silica as templates exhibits the bandgap of 2.25-2.49 eV. After incorporation of $\mathrm{Cr}$ into the $\mathrm{CN}$ structure, the bandgap of the material is decreased from 2.7 to $2.2 \mathrm{eV}$. The lower bandgap is highly necessary for the photocatalytic application involving water splitting or photocatalytic degradation. The presence of $\mathrm{Cr}$ based nanoparticles will also provide catalytically active redox sites or more basicity to the materials. It has been reported that ${ }^{24}$ the bandgap of porous carbon nitride materials could be tuned in the range of 2.26 to $2.69 \mathrm{eV}$ with a simple adjustment of the type and nature of the bonding structure and/or the nitrogen contents. It is worth noting that we have successfully prepared the Cr-MCN-10 with a much lower bandgap in the presence of chromium without any doping reagent.

X-ray photoelectron spectroscopy (XPS) analysis was also carried out for the Cr-MCN-10-1.5 and the results are shown in Fig. 5A-D. The XPS survey spectrum shows the peaks related to $\mathrm{Cr}, \mathrm{C}, \mathrm{N}$ and $\mathrm{O}$ (Fig. 5A). Interestingly, the intensity of the nitrogen peaks increases with increasing the amount of AG in the synthesis mixture. This indicates that the nitrogen content of the materials increases with the addition of more amount of AG. The presence of the $\mathrm{O}$ peak confirms the presence of a trace amount of oxygen which might have originated from the adsorbed $\mathrm{CO}_{2}$ or chromium oxide nanoparticles. This result is consistent with the data obtained from EDS analysis. The chemical bonding between carbon, nitrogen and chromium
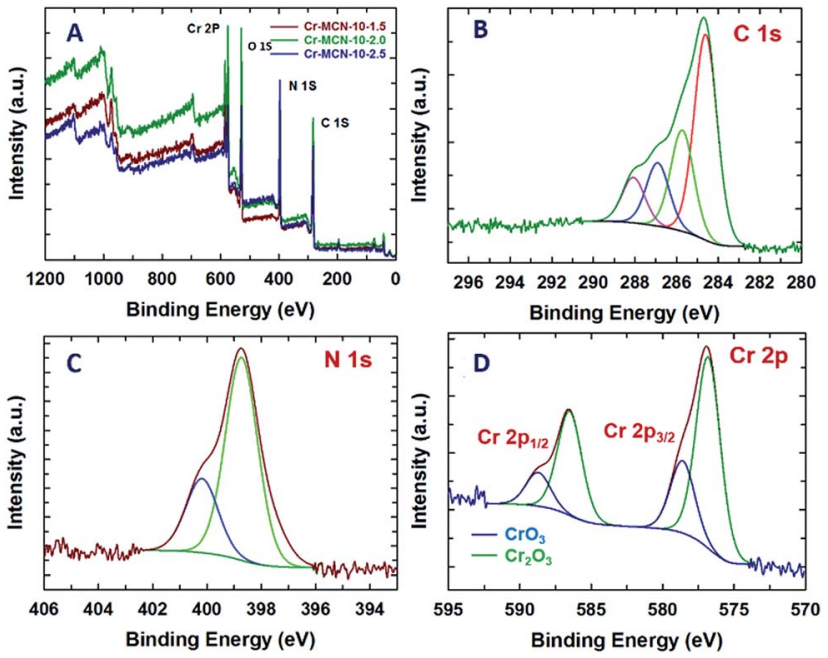

Fig. 5 (A) XPS survey spectra of $C r-M C N-10-X$ samples, (B) deconvoluted $C$ 1s spectra, (C) N 1s spectra and (D) Cr 2p spectra of the $\mathrm{Cr}$ MCN-10-1.5 sample. 
atoms has been obtained from the high resolution $\mathrm{C} 1 \mathrm{~s}, \mathrm{~N} 1 \mathrm{~s}$ and $\mathrm{Cr} 2 \mathrm{p}$ spectra of Cr-MCN-10-1.5 which are shown in Fig. 5. The deconvoluted $\mathrm{C}$ 1s spectrum shows four peaks around 288.1, 286.9, 285.7, and 284.6 eV (Fig. 5B). The large peak at the lowest energy contribution is due to the $\mathrm{sp}^{2}$ hybridized carbon in the sample which is quite different from the sample prepared from mesoporous silica as the template. The peak at $285.7 \mathrm{eV}$ is attributed to the $\mathrm{sp}^{2}$ hybridized carbon bonded to nitrogen inside the aromatic ring whereas the peak at $286.9 \mathrm{eV}$ is ascribed to carbon bonded with nitrogen present in the aromatic tetrazine ring (Scheme $\mathrm{S} 1 \dagger$ ). ${ }^{21}$ The highest energy contribution at $288.1 \mathrm{eV}$ might have originated from the carbon bonded with the trigonal nitrogen atoms. ${ }^{24,42}$ In the $\mathrm{N}$ 1s XPS spectra, we can clearly observe two strong peaks centered at 398.7 and $400.2 \mathrm{eV}$ (Fig. 5C). The lowest energy contribution is assigned to nitrogen atoms bonded with $\mathrm{sp}^{2}$ hybridised carbon whereas the highest energy contribution is attributed to the trigonal nitrogen phase bonded to $\mathrm{sp}^{2}$ hybridised carbon. The observed binding energies of $\mathrm{C} 1 \mathrm{~s}$ and $\mathrm{N} 1 \mathrm{~s}$ spectra closely matched with the reported binding energies of MCN materials. ${ }^{\mathbf{4 8 , 4 9}}$ The Cr $2 \mathrm{p}$ spectrum reveals that the binding energies of $\mathrm{Cr} 2 \mathrm{p}_{3 / 2}$ and $\mathrm{Cr} 2 \mathrm{p}_{1 / 2}$ fall at 576.5 and $586.6 \mathrm{eV}$, respectively (Fig. 5D). These peaks are attributed to $\mathrm{Cr}^{3+}$ and $\mathrm{Cr}^{6+}$ in $\mathrm{Cr}_{2} \mathrm{O}_{3}$ and $\mathrm{CrO}_{3}$ nanoparticles in MCN. Both the $\mathrm{Cr} 2 \mathrm{p}_{3 / 2}$ and $\mathrm{Cr} 2 \mathrm{p}_{1 / 2}$ peaks are deconvoluted into two valence states: low-valence $\left(\mathrm{Cr}^{3+}\right)$ at $576.6 \mathrm{eV}$ and high-valence $\left(\mathrm{Cr}^{6+}\right)$ at $579.3 \mathrm{eV}$, respectively, indicating a mixed phase of $\mathrm{Cr}_{2} \mathrm{O}_{3}$ and $\mathrm{CrO}_{3}$ nanoparticles. ${ }^{50-52}$ These results confirm that ultra-fine chromium oxide nanoparticles which are formed on the porous channels of MCN after the decomposition of the MIL-100(Cr) template are present in the form of chromium oxide in Cr-MCN-10.

\section{4 $\mathrm{CO}_{2}$ and $\mathrm{H}_{2}$ adsorption analysis}

The presence of a highly basic nitrogen content in Cr-MCN-10- $X$ samples with a large surface area encourages us to evaluate them for the $\mathrm{CO}_{2}$ adsorption. The $\mathrm{CO}_{2}$ capturing ability of $\mathrm{Cr}-$ MCN-10- $X$ samples was investigated at high pressures up to 30 bars and at different temperatures and the results are shown in Fig. 6A-D. Fig. 6A shows the $\mathrm{CO}_{2}$ adsorption isotherms of $\mathrm{Cr}$ MCN-10 materials prepared with different amounts of AG precursors. Among the samples studied, Cr-MCN-10-1.5 showed the highest $\mathrm{CO}_{2}$ adsorption capacity of $16.8 \mathrm{mmol} \mathrm{g}^{-1}$ at the adsorption temperature of $0{ }^{\circ} \mathrm{C}$ and at $30 \mathrm{bar}$. This large $\mathrm{CO}_{2}$ adsorption capacity is attributed to the large surface area, micropore area, and nitrogen functionalities on the surface which provide the basic sites. Interestingly, Cr-MCN-10-2.5 exhibits the higher adsorption capacity $\left(10.7 \mathrm{mmol} \mathrm{g}^{-1}\right)$ than Cr-MCN-10-2.0 (10.0 $\mathrm{mmol} \mathrm{g}^{-1}$ ) even though the latter has a higher specific surface area than the former. This is explained by the fact that $\mathrm{Cr}-\mathrm{MCN}-10-2.5$ has a higher nitrogen content which provides more basic sites than that of Cr-MCN-10.2.0. However, Cr-MCN-10-1.5 has the lowest nitrogen content but it is still found to be the best adsorbent. It is surmised that the presence of a large amount of chromium oxide nanoparticles in this material provides a synergetic effect with more basicity that enhances the amount of $\mathrm{CO}_{2}$ adsorbed. This result confirms
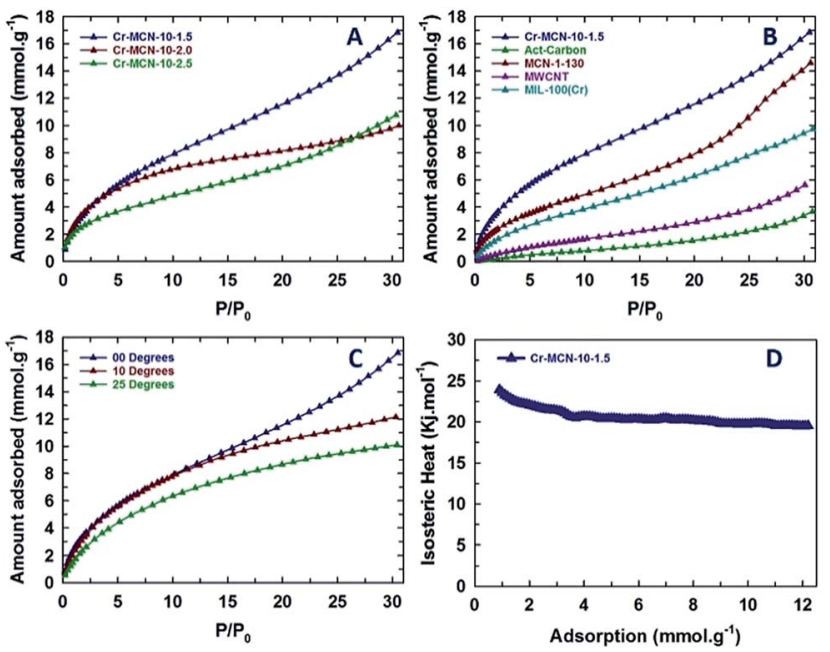

Fig. 6 (A) $\mathrm{CO}_{2}$ adsorption isotherms of $\mathrm{Cr}-\mathrm{MCN}-10-X$ samples at zero degrees, (B) comparison of $\mathrm{CO}_{2}$ adsorption isotherms of the $\mathrm{Cr}-\mathrm{MCN}$ 10-1.5 sample with other well established porous materials, (C) $\mathrm{CO}_{2}$ adsorption isotherms of the $\mathrm{Cr}-\mathrm{MCN}-10-1.5$ sample in different temperature ranges and (D) heat of adsorption plot of the $\mathrm{Cr}-\mathrm{MCN}$ 10-1.5 sample.

that not only the nitrogen content but also large specific surface area and metal oxide nanoparticles are critical to enhance the $\mathrm{CO}_{2}$ adsorption capacity. It is also found that the amount of $\mathrm{CO}_{2}$ adsorbed can be controlled with a simple adjustment of the chromium oxide nanoparticles in the pore channels of the CrMCN-10.

In order to verify the superiority of the Cr-MCN-10 materials for the $\mathrm{CO}_{2}$ adsorption, the $\mathrm{CO}_{2}$ adsorption capacity of $\mathrm{Cr}-\mathrm{MCN}$ 10-1.5 was compared with those of the template, MIL-100(Cr), activated carbon, multiwalled carbon nanotube and MCN prepared from mesoporous silica templates. It is interesting to note that the $\mathrm{CO}_{2}$ adsorption capacity of Cr-MCN-10-1.5 is much higher than those of the template MIL-100(Cr) $\left(9.8 \mathrm{mmol} \mathrm{g}^{-1}\right)$, activated carbon $\left(3.6 \mathrm{mmol} \mathrm{g}^{-1}\right)$, and other carbon nitride MCN1-130 (14.5 $\left.\mathrm{mmol} \mathrm{g}^{-1}\right) \cdot{ }^{6,12,36,37}$ These results demonstrate the superior nature of the $\mathrm{Cr}-\mathrm{MCN}-10$ that was prepared in a single step without any hazardous $\mathrm{HF}$ washing procedure for the $\mathrm{CO}_{2}$ adsorption. The effect of adsorption temperature on the $\mathrm{CO}_{2}$ adsorption capacity was also investigated. Fig. 6C shows the $\mathrm{CO}_{2}$ adsorption isotherms of Cr-MCN-10-1.5 measured at different temperatures $\left(0,10\right.$ and $\left.25{ }^{\circ} \mathrm{C}\right)$. As can be seen in Fig. 6C, the amount of $\mathrm{CO}_{2}$ adsorbed increases with increasing the analysis temperature and the adsorption temperature of $0{ }^{\circ} \mathrm{C}$ was found to be the best. The nature of the interaction between the adsorbate and the adsorbent was analyzed by calculating the isosteric heat of adsorption using the ClausiusClapeyron equation. The sample exhibits a heat of adsorption of $25 \mathrm{~kJ}$ at low $\mathrm{CO}_{2}$ adsorption to $21 \mathrm{~kJ}$ as the amount of $\mathrm{CO}_{2}$ is increased. The value of heat of adsorption at higher $\mathrm{CO}_{2}$ loading is almost similar to those of MCN-1 materials but higher than those of mesoporous carbon-based adsorbents. This clearly explains the role of nitrogen functionalities and chromium oxides in the $\mathrm{CO}_{2}$ adsorption. In addition, the excellent $\mathrm{CO}_{2}$ 

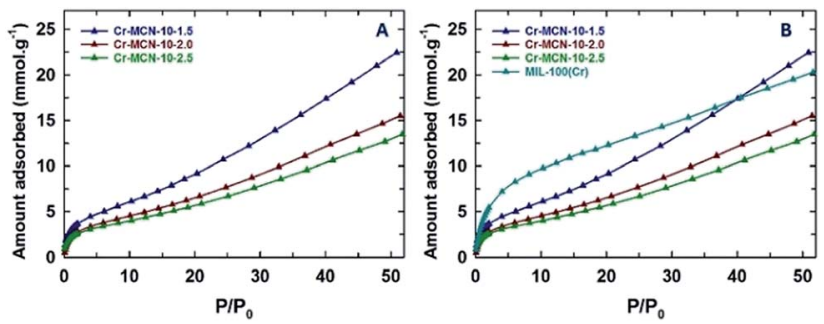

Fig. 7 (A) $\mathrm{H}_{2}$ adsorption isotherms of $\mathrm{Cr}-\mathrm{MCN}-10-\mathrm{X}$ samples at zero degrees and (B) comparison of $\mathrm{H}_{2}$ adsorption isotherms of $\mathrm{Cr}-\mathrm{MCN}$ 10-X samples with the template MIL-100(Cr).

adsorption performance is the result of weak van der Waals forces and the capillary condensation effect due to the mesoporous and microporous nature of the pores and the chemical bonding with the $\mathrm{CO}_{2}$ and specific functionalities owing to the presence of abundant Lewis base sites in the active catalyst. ${ }^{53}$

The hydrogen adsorption properties of the prepared $\mathrm{Cr}$ MCN-10 samples were also investigated and the results are compared with those of the template MIL-100(Cr) (Fig. 7). It should be noted that Cr-MCN-10-1.5 registered the hydrogen adsorption capacity of $22.5 \mathrm{mmol} \mathrm{g}^{-1}$ which is much higher than those of other Cr-MCN-10 samples and the template MIL$100(\mathrm{Cr})$. Again, the higher hydrogen adsorption capacity of this material is attributed to the large surface area and the presence of a small amount of chromium oxide nanoparticles that offer a synergistic effect which is crucial for enhancing the amount of hydrogen adsorption. All these results clearly confirm that the prepared materials are excellent candidates for the adsorption of hydrogen or $\mathrm{CO}_{2}$ molecules and have the potential to replace the existing highly ordered porous materials owing to their ease of preparation and low cost.

\section{Conclusions}

In this work, we demonstrated a novel route for a single step synthesis of porous carbon nitrides with ultra-fine metal oxide nanoparticles using MIL-100(Cr) as a sacrificial template without any toxic HF-based template removal process. We demonstrated that MCN materials can be decorated with ultrafine chromium oxide nanoparticles without any post-synthetic treatment. The prepared mesoporous carbon nitride materials exhibited much higher specific surface areas and pore volumes than the reported mesoporous carbon nitrides prepared from mesoporous silica templates. XPS, EELS and FT-IR results confirmed that the Cr-MCN-10 materials have the typical graphitic $\mathrm{CN}$ chemical structure that is composed of tetrazine moieties. We also found that the bandgap of the functionalized Cr-MCN-10 material (2.2 eV) was much lower than those of nonporous MCN and other MCN materials (2.7 eV), which is very beneficial for photocatalytic applications involving water splitting. We also demonstrated that the Cr-MCN-10 samples showed much higher $\mathrm{CO}_{2}$ and hydrogen adsorption capacity than the template, activated carbon, multiwalled carbon nanotubes and porous MCN nanostructures prepared from mesoporous silica templates. We concluded that these exciting adsorption properties are due to the presence of large specific surface area, micropore surface area, a large number of basic nitrogen functionalities and the synergistic effects provided by the ultra-fine chromium oxide nanoparticles. We believe that the approach presented in this work is quite simple and could be used for the preparation of a series of $\mathrm{CN}$ materials with different metal oxide nanoparticles using various metal organic framework materials as templates. Moreover, the prepared materials also have the potential to replace the currently available adsorbent materials for carbon capture and hydrogen adsorption and could be used as catalysts for various redoxbased catalytic reactions.

\section{Conflicts of interest}

There are no conflicts of interest to declare.

\section{Acknowledgements}

One of the authors A. Vinu acknowledges the Australian Research Council for the Future Fellowship, ARC Discovery Project Awards (DP 150104828; DP 170104478; FT100100970), and University of South Australia for start-up grants.

\section{References}

1 D. Y. C. Leung, G. Caramanna and M. M. Maroto-Valer, Renewable Sustainable Energy Rev., 2014, 39, 426-443.

2 T. Seki, Y. Kokubo, S. Ichikawa, T. Suzuki, Y. Kayaki and T. Ikariya, Chem. Commun., 2009, 349-351.

3 R. A. Betts, O. Boucher, M. Collins, P. M. Cox, P. D. Falloon, N. Gedney, D. L. Hemming, C. Huntingford, C. D. Jones, D. M. Sexton and M. J. Webb, Nature, 2007, 448, 1037-1041. 4 J. Meyer, Nature, 2008, 455, 733.

5 M. Z. Jacobson, Energy Environ. Sci., 2009, 2, 148-173.

6 L. Liu, F. Y. Wang, G. S. Shao and Z. Y. Yuan, Carbon, 2010, 48, 2089-2099.

7 M. Sevilla, P. Valle-Vigon and A. B. Fuertes, Adv. Funct. Mater., 2011, 21, 2781-2787.

8 L. Liu, F. Y. Wang, G. S. Shao, T. Y. Ma and Z. Y. Yuan, Carbon, 2010, 48, 2660-2664.

9 C. Pevida, T. C. Drage and C. E. Snape, Carbon, 2008, 46, 1464-1474.

10 J. L. Zimmerman, R. Williams, V. N. Khabashesku and J. L. Margrave, Nano Lett., 2001, 1, 731-734.

11 Q. Li, J. P. Yang, D. Feng, Z. X. Wu, Q. L. Wu, S. S. Park, C. S. Ha and D. Y. Zhao, Nano Res., 2010, 3, 632-642.

12 Q. F. Deng, L. Liu, X. Z. Lin, G. H. Du, Y. P. Liu and Z. Y. Yuan, Chem. Eng. J., 2012, 203, 63-70.

13 M. Kawaguchi, S. Yagi and H. Enomoto, Carbon, 2004, 42, 345-350.

14 A. Thomas, A. Fischer, F. Goettmann, M. Antonietti, J. O. Muller, R. Schlogl and J. M. Carlsson, J. Mater. Chem., 2008, 18, 4893-4908.

15 Y. Qiu and L. Gao, Chem. Commun., 2003, 2378-2379.

16 E. Kroke and M. Schwarz, Coord. Chem. Rev., 2004, 248, 493532. 
17 M. Groenewolt and M. Antonietti, Adv. Mater., 2005, 17, 1789-1792.

18 A. Vinu, K. Ariga, T. Mori, T. Nakanishi, S. Hishita, D. Golberg and Y. Bando, Adv. Mater., 2005, 17, 1648-1652.

19 Y. S. Jun, W. H. Hong, M. Antonietti and A. Thomas, Adv. Mater., 2009, 21, 4270-4274.

20 E. Z. Lee, Y. S. Jun, W. H. Hong, A. Thomas and M. M. Jin, Angew. Chem., Int. Ed., 2010, 49, 9706-9710.

21 A. Vinu, Adv. Funct. Mater., 2008, 18, 816-827.

22 S. N. Talapaneni, J. H. Lee, S. H. Je, O. Buyukcakir, T. W. Kwon, K. Polychronopoulou, J. W. Choi and A. Coskun, Adv. Funct. Mater., 2017, 27, 1604658.

23 A. Vinu, P. Srinivasu, D. P. Sawant, T. Mori, K. Ariga, J. S. Chang, S. H. Jhung, V. V. Balasubramanian and Y. K. Hwang, Chem. Mater., 2007, 19, 4367-4372.

24 S. N. Talapaneni, G. P. Mane, A. Mano, C. Anand, D. S. Dhawale, T. Mori and A. Vinu, ChemSusChem, 2012, 5, 700-708.

25 J. Liu, P. K. Thallapally, B. P. McGrail, D. R. Brown and J. Liu, Chem. Soc. Rev., 2012, 41, 2308-2322.

26 B. Wang, A. P. Cote, H. Furukawa, M. O'Keeffe and O. M. Yaghi, Nature, 2008, 453, 207-211.

27 A. L. Dzubak, L. C. Lin, J. Kim, J. A. Swisher, R. Poloni, S. N. Maximoff, B. Smit and L. Gagliardi, Nat. Chem., 2012, 4, 810-816.

28 A. Torrisi, R. G. Bell and C. Mellot-Draznieks, Cryst. Growth Des., 2010, 10, 2839-2841.

29 H. Furukawa, N. Ko, Y. B. Go, N. Aratani, S. B. Choi, E. Choi, A. O. Yazaydin, R. Q. Snurr, M. O'Keeffe, J. Kim and O. M. Yaghi, Science, 2010, 329, 424-428.

30 D. Marton, K. J. Boyd, A. H. Al-Bayati, S. S. Todorov and J. W. Rabalais, Phys. Rev. Lett., 1994, 73, 118-121.

31 S. L. James, Chem. Soc. Rev., 2003, 32, 276-288.

32 G. Férey, C. Serre, C. Mellot-Draznieks, F. Millange, S. Surblé, J. Dutour and I. Margiolaki, Angew. Chem., Int. Ed., 2004, 43, 6296-6301.

33 M. Latroche, S. Surble, C. Serre, C. Mellot-Draznieks, P. L. Llewellyn, J. H. Lee, J. S. Chang, S. H. Jhung and G. Ferey, Angew. Chem., Int. Ed., 2006, 45, 8227-8231.

34 Y. Zhong, M. Jaidann, Y. Zhang, G. X. Zhang, H. Liu, M. I. Ionescu, R. Y. Li, X. L. Sun, H. Abou-Rachid and L. S. Lussier, J. Phys. Chem. Solids, 2010, 71, 134-139.

35 K. S. Lakhi, W. S. Cha, S. Joseph, B. J. Wood, S. S. Aldeyab, G. Lawrence, J. H. Choy and A. Vinu, Catal. Today, 2015, 243, 209-217.
36 M. N. Timofeeva, V. N. Panchenko, N. A. Khan, Z. Hasan, I. P. Prosvirin, S. V. Tsybulya and S. H. Jhung, Appl. Catal., A, 2017, 529, 167-174.

37 M. N. Timofeeva, V. N. Panchenko, A. A. Abel, N. A. Khan, I. Ahmed, A. B. Ayupov, K. P. Volcho and S. H. Jhung, J. Catal., 2014, 311, 114-120.

38 P. L. Llewellyn, S. Bourrelly, C. Serre, A. Vimont, M. Daturi, L. Hamon, G. De Weireld, J. S. Chang, D. Y. Hong, Y. Kyu Hwang, S. Hwa Jhung and G. Ferey, Langmuir, 2008, 24, 7245-7250.

39 S. N. Talapaneni, G. P. Mane, D. Park, K. S. Lakhi, K. Ramadass, S. Joseph, W. M. Skinner, U. Ravon, K. AlBahily and A. Vinu, J. Mater. Chem. A, 2017, 5, 18183-18192.

40 X. Jin, V. V. Balasubramanian, S. T. Selvan, D. P. Sawant, M. A. Chari, G. Q. Lu and A. Vinu, Angew. Chem., Int. Ed., 2009, 48, 7884-7887.

41 S. N. Talapaneni, S. Anandan, G. P. Mane, C. Anand, D. S. Dhawale, S. Varghese, A. Mano, T. Mori and A. Vinu, J. Mater. Chem., 2012, 22, 9831-9840.

42 G. P. Mane, D. S. Dhawale, C. Anand, K. Ariga, Q. M. Ji, M. A. Wahab, T. Mori and A. Vinu, J. Mater. Chem. A, 2013, 1, 2913-2920.

43 G. P. Mane, S. N. Talapaneni, K. S. Lakhi, H. Ilbeygi, U. Ravon, K. Al-Bahily, T. Mori, D. H. Park and A. Vinu, Angew. Chem., Int. Ed., 2017, 56, 8481-8485.

44 D. H. Park, K. S. Lakhi, K. Ramadass, M. K. Kim, S. N. Talapaneni, S. Joseph, U. Ravon, K. Al-Bahily and A. Vinu, Chem.-Eur. J., 2017, 23, 10753-10757.

45 T. L. Daulton and B. J. Little, Ultramicroscopy, 2006, 106, 561573.

46 M. Kim, S. Hwang and J. S. Yu, J. Mater. Chem., 2007, 17, 1656-1659.

47 W. J. Ong, L. L. Tan, S. P. Chai and S. T. Yong, Dalton Trans., 2015, 44, 1249-1257.

48 W. J. Son, J. S. Choi and W. S. Ahn, Microporous Mesoporous Mater., 2008, 113, 31-40.

49 C. Chen, J. Kim, D. A. Yang and W. S. Ahn, Chem. Eng. J., 2011, 168, 1134-1139.

50 P. L. Qin, H. W. Lei, X. L. Zheng, Q. Liu, H. Tao, G. Yang, W. J. Ke, L. B. Xiong, M. C. Qin, X. Z. Zhao and G. J. Fang, Adv. Mater. Interfaces, 2016, 3, 1500799.

51 Y. Jeon, D. H. Park, J. I. Park, S. H. Yoon, I. Mochida, J. H. Choy and Y. G. Shul, Sci. Rep., 2013, 3, 2902.

52 Y. P. Chen, K. Ding, L. Yang, B. Xie, F. Q. Song, J. G. Wan, G. G. Wang and M. Hana, Appl. Phys. Lett., 2008, 92, 173112. 53 V. Zelenak, M. Badanicova, D. Halamova, J. Cejka, A. Zukal, N. Murafa and G. Goerigk, Chem. Eng. J., 2008, 144, 336-342. 